\title{
¿Hacia dónde va el FMLN? Análisis de la crisis del FMLN y las posibilidades de superación
}

1. Introducción: identificación y reconocimiento de la crisis en el FMLN

En los momentos de crisis de asociaciones humanas con fines objetivos, así como también en crisis de tipo personal, solemos hacernos 3 preguntas básicas: ¿de dónde venimos, quiénes somos y hacia dónde vamos? Y aunque estas preguntas no sean apropiadas únicamente para momentos de crisis, sería conveniente que en las actuales circunstancias se las hiciera el FMLN. Pero antes de ello es necesario identificar la crisis misma.

Es muy poco probable que la crisis que en la actualidad vive el FMLN se deba, predominantemente, a una lucha ideológica. Este tipo de crisis supondría la existencia, entre otras cosas, de un cuerpo objetivo y ordenado de ideas bastante definido que el partido cree y confiesa, una militancia sumamente ideologizada y cualificada; del mismo modo que personas o grupos que pretendan socavar o modificar ese cuerpo doctrinal frente a otro que quiera defenderlas. Pero ninguna de estas con- diciones existe en el FMLN y, por lo tanto, la raíz de la crisis puede ser cualquiera otra, menos un problema en esencia ideológico' . Sin embargo, resulta más gratificante, cómodo y elegante el enmascarar una lucha hegemónica bajo la forma de la defensa de la pureza ideológica o doctrinal, que presentarla como una disputa de poder, intereses personales o grupales. En este sentido, hay que desideologizar la ideologización de la crisis en el FMLN, pero también se debe ideologizar su superación.

Tampoco hay que buscar la raíz de la crisis en los resultados de las últimas elecciones. Un fracaso o una derrota en un grupo o persona bastante maduros y con ideas y fines objetivos, suele ser la ocasión más privilegiada para un examen de sus ideas y su modo de proceder con miras al resurgimiento personal o político, y no la causa de su hundimiento o de cargar a otros la propia responsabilidad del fracaso. En todo caso, el fracaso electoral no es la causa de la crisis, sino un fenómeno de la misma y quizás el más importante.

1. Algunas personas y grupos, dentro y fuera del FMLN, han querido ver la raíz de la crisis - tal vez por ingenuidad, malicia o simplismo- en una disputa entre defensores de una ortodoxia marxista frente a un grupo socialdemócrata. Nada más equivocado que esto: la formación marxista de la dirigencia del FMLN, tanto de los así llamados "ortodoxos" como "renovadores" y otros subpartidos, no llega, en general, ni a un conocimiento del Manifiesto del Partido Comunista y de los Manuscritos del 44. Y lo mismo sucede con el conocimiento de los postulados básicos de la socialdemocracia. El FMLN es actualmente un partido bastante pragmático, y este tipo de disquisiciones están ausentes de la discusión en un partido con tales características. 


\section{La pluralidad de causas de la crisis del FMLN}

La raíz de la crisis del FMLN debemos buscarla en una pluralidad de causas. Cualquier intento de una comprensión monocausal de la crisis nos parece incompleto e incorrecto. $Y$ dentro de dichas causas, mencionaremos las más relevantes.

(1) El FMLN no se preparó internamente para el nuevo escenario, que suponía su conversión en partido político tras el fin de la lucha armada. El paso de ser una fuerza militar a convertirse en un partido no es automático ni se da con la mera desmovilización y entrega de las armas. La astucia militar no se transforma de manera automática en astucia política. Con ello se cayó en una desactualización y en un desfase para los nuevos desafíos que presentaba el nuevo escenario político, tras la firma de los acuerdos de paz.

(2) El FMLN carece de un "credo político" básico, claramente definido y común a su membresía, de tal manera que toda su militancia sepa cuando está dentro y cuando está fuera o, dicho en otros términos, no hay un encuadre de ideales básicos comunes que sean la referencia fundamental de la razón de ser y las aspiraciones del partido. Las ideas que hay al respecto son demasiado bomosas y desordenadas. En la guerra, en cambio, existía un cuerpo básico de ideas comunes, compartidas incluso por mucha gente fuera de sus filas y con las que muchos terminaban simpatizando. Muchas de estas ideas, algunas utópicas, atraían y arrastraban a la gente, aun a la más diversa y plural. Y por eso nunca podría entenderse la necesidad de conformar un credo político básico como una amenaza al pluralismo, sino como una ayuda a la articulación y coherencia del desorden de ideas que actualmente existe, sin un núcleo básico que las articule. Se debe promover y respetar la pluralidad, pero a partir de un cuerpo básico de ideas, actualizables y vivas, sujetas a diversos desarrollos y actualizaciones. No se puede hablar de pluralismo sin un fondo común de ideas. Muchos pueblos antiguos, en especial los de carácter tribal, lograron articular la pluralidad y la diferencia con base en la conformación de un credo político religioso básico. El conformar y tener dicho credo ayudaría al FMLN a desideologizar la lucha interna, pues si este núcleo básico existiera, difícilmente la lucha interna actual podría enmarcararse como "lucha ideológica" o "lucha de creencias".
(3) La forma de gobierno interno del FMLN no ha logrado separar y distinguir lo que es un liderazgo institucional de un liderazgo carismático. Ambas formas no tienen por qué contradecirse. En la guerra estas formas de liderazgo se concentraban en las mismas personas - lo cual es propio de un liderazgo de tipo caudillista-, pero eso ya no tiene que ser así necesariamente, aunque son dos formas que tienen que coexistir y han coexistido hasta la muerte del portador o los portadores del carisma en muchas instituciones que tienen un origen carismático. Pero esta coexistencia debe ser normada en forma institucional, aunque no sin tensiones. Cuando un grupo con liderazgo carismático se institucionaliza y no se administra con sabiduría, la tensión normal entre institución y carisma fácilmente puede caer en dos peligros: el sobrepeso y anquilosamiento institucional o la formación de sectas cismáticas.

(4) Para la nueva fase tras los acuerdos de paz, ya como partido político, el FMLN no se preparó para un imperativo político de primer orden que debía enfrentar para convertirse en una opción de poder: la masificación de su membresía. Un grupo en su forma carismática nunca puede ser masivo, pero un partido institucionalizado y de origen carismático sí. Al no estar preparados para la masificación, esto se convirtió no sólo en nuevos adeptos e incremento de la militancia, sino también en nuevos problemas: se cayó rápidamente en la pérdida o desdibujamiento de ideales, sin poder sustituirlos por otros; se dio un relajamiento de la moral; se perdió el sentido de camaradería y compañerismo. Muchos entraron al partido sin saber por qué y para qué; otros entraron llevando sus propias tradiciones políticas, las que, al no contar el FMLN con un credo político básico, podrían haber propiciado el sincretismo político, o incluso haberse impuesto frente a la debilidad ideológica del FMLN. Y todo esto, y no por responsabilidad de los advenedizos o recién llegados, hizo que el FMLN entrara rápidamente en el proceso de conversión en un partido tradicional y pragmático, en el que actualmente se encuentra.

(5) Tras la adquisición de una ingente cuota de poder a través de gobiernos municipales (54) y diputaciones (27), algunos cuadros y subgrupos dentro y fuera del FMLN han visto que es mejor vivir de la política que vivir para la política. La mayoría de los que ahora son funcionarios por elección 
popular quisieran continuar siéndolo frente a otros que aspiran a candidaturas. Es más, algunos incluso propugnan una reforma estatutuaria, por razones de pureza ideológica, para que sea posible aspirar a un tercer período en un cargo de elección popular, cosa expresamente prohibida en la actualidad. Y éste no es un problema de corrientes o tendencias, sino que trasciende, en general, a todo el partido, aunque es más manifiesto en aquellos que enmascaran sus pretensiones en aras de la pureza ideológica. Algunos, en su falso análisis, creen que obtener una candidatura es equivalente a ganar las elecciones. Poco se mira a las necesidades y a la captatio benevolentiae $^{2}$ del electorado, a los retos que presenta el cargo al que se aspira y a la idoneidad ${ }^{3}$ y cualidades morales del candidato: candidaturas fuera de estos criterios básicos no tienen razón de ser y, todavía peor, si con la candidatura el aspirante pretende resolver sus problemas económicos o existenciales. El FMLN debería responder a los problemas existenciales o materiales de sus cuadros sin necesidad de que se caiga en semejantes aberraciones, aunque la mera crisis existencial o material no sea per se un impedimento para una candidatura porque, por otro lado, podrían existir funcionarios actuales o potenciales, con solvencia económica, que consideraran la actividad política como una extensión de su quehacer empresarial o profesional. Ninguna de ambas situaciones, por sí misma, es garantía u obstáculo de una buena o mala candidatura.

(6) Por último, el FMLN carece de una política institucional de formación y cualificación política de sus cuadros y militantes. $Y$ esta carencia se ha manifestado de varias formas: conducción impropia del partido en la mayoría de estructuras de gobierno interno, debilidad en el análisis político, falta de lucidez para decir la palabra apropiada en el momento oportuno, decisiones equivocadas en la escogitación de candidatos a puestos de elección popular, gestiones municipales flojas y desgastantes. Sin una adecuada decisión institucional

que apueste a la formación y cualificación política de los cuadros y militantes, el FMLN tiene escasas posibilidades de convertirse en una opción de poder, a no ser por inercia, desgaste de la derecha o por un milagro político, pero en cualquiera de estos casos siempre se haría un mal papel.

Estas son, a mi juicio, las principales causas de la crisis del FMLN. Hay que reconocerlas e identificarlas, pues de lo contrario no se podrán superar. La crisis que no se identifica y reconoce, no se supera.

\section{Elementos esenciales para superar la crisis}

Una vez identificada la crisis del FMLN, y si nuestro análisis es correcto, podemos ahora indicar los elementos esenciales para la superación de la misma. Nos vamos a mover aquí en una perspectiva fundamental, sin llegar a proponer medidas concretas, aunque la tentación de mencionar alguna de ellas no pueda ser del todo superada.

\subsection{La conformación de un credo político bási- co}

Una de las cosas que más sorprende en la actual militancia del FMLN es la disimilitud en las creencias políticas: se carece de un núcleo o conjunto de ideales básicos comunes a toda la militancia y con los que ésta se identifique, y a partir

2. "Captación de la buena voluntad", es decir, tratar de captar o cautivar la simpatía de los electores.

3. Convendría recordar a todos los aspirantes que para que los marineros se disputen el timón del barco, como dice Platón, es necesario que tengan conocimientos "del arte del piloto" (Cf. Platón, La República, Libro VI), y esto sin ánimos de ser excluyentes, sino de llamar a la reflexión. 
del cual se pueda hablar de pluralismo. No hay un complejo de ideas a las que todos se adhieran. Hace falta un cuadro fundamental que marque los límites de lo que se cree y se quiere. Un verdadero credo político no va contra el pluralismo, sino contra la promiscuidad en las concepciones políticas.

El credo político de un partido que surge de un movimiento revolucionario armado que aspiraba al socialismo, no puede dejar de contener, en las nuevas circunstancias, ideas firmes y perennes: unos fines objetivos concretos, unos principios abstractos y una utopía que constituyan un fondo estable, inamovible, pero actualizable. En este sentido, el FMLN debe ser un partido ideológico, es decir, que tenga una "concepción del mundo" o Weltanschauung, como se dice en la filosofía alemana. Esto ayudaría, por un lado, a que la adhesión al partido sea racional y, por otro, impediría que se convierta en un partido para la mera cacería de votos.

\subsection{La necesidad de una definición del partido}

En la teoría política clásica existen varias formas de ser de los partidos políticos. Algunas deben ser rechazadas radicalmente como modelo político ejemplar para el FMLN: los partidos que aspiran a que sus líderes lleguen a los más altos cargos públicos; el partido como una maquinaria que se dedica a la "caza de cargos públicos"; los que consideran el Estado como una institución de prebendas; el partido como una sociedad cerrada o testimonial o, lo que es peor, un partido estamental, clasista o de patronazgo ${ }^{4}$.

El FMLN debería ser, en cambio, un partido con fines objetivos y orientado hacia ellos, que aspire a representar la voluntad política de la mayoría de salvadoreños y que tenga un credo político de carácter firme y perenne. No puede ser un partido que modifique su proyecto político según las circunstancias o coyunturas electorales, pero tampoco puede ser un partido cerrado e incapaz de actualizarse. En este sentido, el FMLN debería ser un partido altamente ideológico, que tenga fines objetivos y racionales, así como un credo político fundamental, con una militancia viva, definida y activa. La militancia en un partído así es una militancia racional, no emotiva, irracional u opor- tunista; pero además es una militancia que sabe lo que quiere y hacia dónde va.

Ser un partido ideológico no es un anacronismo ni es contrario a la concepción de un partido moderno. Una definición ideológica de un partido, a condición de que sea racional y actualizable, genera mayor estabilidad interna y mucha más mística en su militancia.

\subsection{La necesidad de un liderazgo institucional, racional y democrático}

Un partido moderno e ideológico, como creemos que debería ser el FMLN, necesita un liderazgo institucional, democrático y fuerte. Pero dada nuestra historia, creemos que este liderazgo no debe matar el espíritu ni los fuertes componentes de autoridad carismática que aún le quedan. Sin embargo, debe predominar el liderazgo institucional, pues es ello lo que da estabilidad a una institución; en cambio, un partido fundado predominantemente en una autoridad carismática - llámese ésta "caudillo", "profeta" o "líder"- genera, por su propia naturaleza, inestabilidad e incertidumbre, y podría favorecer subpartidos de carácter semipermanente. La autoridad carismática puede convivir con la autoridad institucional, pero sometida a ésta, aunque se debe estar consciente de que la autoridad institucional nunca debe aspirar a ser aceptada de manera universal en el FMLN.

El liderazgo institucional, o gobierno interno del partido, debe ser el primero en imbuirse del credo político, de la definición del partido y de la formación y cualificación política. Y se debe estar muy consciente de que en un partido, como el que creemos que debería ser el FMLN, es impensable creer que los cargos públicos serán para los líderes y cuadros dirigentes. En un partido como el que aquí se esboza, es el liderazgo institucional el garante y depositario de la tradición del partido, de su credo y sus ideales y, por lo tanto, difícilmente puede aspirar a un cargo público sin socavar los fundamentos del partido.

Pero un liderazgo institucional requiere, además, que sus cuadros de dirección sean personas que conserven lo mejor de la tradición política del FMLN. Es mejor que el gobierno del partido, local y nacional, esté formado, fundamentalmente, por

4. No pretendo entrar en el uso de la terminología clásica para no hacer de estas ideas prácticas un ejercicio académico. 
el homo vetus ("hombre viejo"), cuando sea posible, pero en una sana combinación con el homo novus ("hombre nuevo"). Sí se debe evitar un gobierno de partido de puros "homo novus". Y para esto hay razones de tipo sociológico y político: la militancia y el electorado, en general, sienten más confianza con el que le es más conocido y conservador de una determinada tradición. Se debe evitar en el gobierno del partido al mero advenedizo, a menos que haya sido suficientemente probado.

\subsection{La necesidad de la formación y cualifica- ción política}

El FMLN necesita una estrategia de formación y capacitación de su dirigencia, cuadros intermedios, funcionarios y potenciales dirigentes, una formación política seria, excelente y actualizada a las nuevas circunstancias y desafíos. En el fondo de la crisis del FMLN no hay sólo un problema de intereses, disputas de liderazgo o aspiraciones a candidaturas - por lo demás legítimas y normales en cualquier partido político-, sino también un problema de comprensión de la realidad del país, sus desafíos, el rumbo que hay que seguir para sacar al país adelante, las nuevas realidades económicas, políticas e internacionales, entre otras cosas.

No sólo hay, entonces, un problema de comprensión o desconocimiento de la realidad objetiva en la que se debe actuar y transformar, sino también un problema de incomprensión del instrumento, el partido, que debe impulsar y vanguardizar los cambios que el país necesita.

En un breve diagnóstico sobre la formación y actualización política del FMLN, constatamos que la mayoría de su militancia - situación de la que también participan sus cuadros- carece de un adecuado instrumental teórico-práctico para analizar la realidad del país. La mayoría de la militancia desconoce qué tipo de partido es el FMLN, su naturaleza, su historia, es decir, de dónde viene, qué es y qué quiere. Tampoco hay claridad sobre lo que se quiere ser. Casi nadie puede responder a la pregunta sobre qué tipo de partido es o quiere ser el FMLN.
Una formación política en el FMLN no debería pretender, obviamente, la creación de "espíritus ilustrados", sino la dotación a la militancia de instrumentos básicos de análisis político, la internalización de los ideales políticos, la creación de una mística y un ethos político, y la necesaria actualización de la militancia y del partido a las nuevas realidades nacionales e internacionales.

Para salir de la crisis, por tanto, el FMLN necesita crear, entre otras cosas, una adecuada política de formación y educación política de sus cuadros y militantes. Y esta "escuela" sería el lugar para la difusión y el análisis de las ideas ya mencionadas y para la superación de la formación política concebida como adoctrinamiento o "toma de conciencia".

\subsection{La necesidad de candidaturas razonables}

Una de las experiencias más claras y aleccionadoras de la gestión municipal y legislativa del FMLN, es la necesidad de ordenar y regular los procesos de selección de candidatos a puestos de elección popular. La forma actual de selección de candidatos, basada en la correlación numérica, el problema de género o el respaldo de grupos de poder, no tiene razón de ser si son los únicos criterios válidos que se tienen en cuenta. Hay que mirar por lo menos otros elementos importantes: la idoneidad y moralidad del candidato, las necesidades, expectativas y captación de la simpatía del electorado y las exigencias propias de la función que se va a desempeñar. Es posible armonizar todos estos elementos, pero iniciando desde el punto de partida correcto, el cual no puede ser la correlación numérica o el apoyo de grupos de poder. Dicho en otros términos: es necesaria la racionalidad en los procesos de selección de candidatos, pero también es necesaria la escogitación de candidatos racionales y sensatos ${ }^{5}$. Esto evitaría la aparición de espíritus poco ilustrados en las candidaturas o, lo que sería todavía peor, la emergencia de espíritus bastardos.

La ausencia de una política de selección de candidatos, ordenada y regulada racionalmente ha

5. Tal vez ayuden a este proceso algunas de las enseñanzas de Platón: (1) se debe confiar la autoridad a aquellos que no están celosos de poseerla, pues, de otra manera, la rivalidad hará surgir disputas; y (2) conviene que acepten un mando aquellos que, mejor instruidos que nadie en la ciencia de gobernar, tengan otra vida y otros honores que prefieran a los que la vida política les ofrece (Cf. La República, Libro VII). 
hecho mucho daño al FMLN, de tal manera que hay quienes se preguntan: ¿qué sentido tiene haber ganado 54 alcaldías y 27 diputados, si esto no sirvió para acumular y fortalecer al partido y que la buena gestión que se debería haber hecho fuera la principal carta de presentación en las elecciones presidenciales de 1999? ¿Acaso será razón suficiente ganar numerosos gobiernos municipales y diputaciones para emplear a cuadros y militantes?

Sin esta política, el terreno de las ambiciones desmedidas e irracionales podría continuar minando al partido, sobre todo cuando a lo que se aspira es desproporcional a las cualidades del aspirante, pues no todos los que en el FMLN desean una candidatura han aprendido y practican la lección de Julio César, que cuando pasaba por un miserable pueblo de los Alpes exclamó: "prefiero ser el primero en este pueblo que el segundo en Roma".

\subsection{La necesidad de una nueva ética política}

Un partido político de izquierda, con la historia y como debería ser el FMLN, no puede seguir haciendo lo mismo, de igual manera y en nuevas circunstancias. Las relaciones en el partido ya no son tan primarias e inmediatas como eran en el tiempo de la guerra. Las nuevas situaciones ya no permiten la vieja camaradería y fraternidad revolucionarias. Esta perspectiva de alteridad, de ver en el otro al compañero y a un sujeto moral, se ha perdido casi en su totalidad. La lucha de poder ha deshumanizado al partido, sin que aparezca una nueva forma de relación política fundada en principios morales válidos. Y lo mismo podría decirse, en general; de aquellos que ejercen un cargo público.

Por todo esto es necesario que el FMLN cree una nueva ética política y una nueva relación entre ética y política. Tal vez las viejas relaciones inmediatas de antaño, en que el individuo lleno de ideales vivía para la política, no sean reproducibles en la actualidad, pero sí es necesario mantener el principio de que el partido busca la transformación social, el actuar responsablemente en la sociedad, dignificar la actividad política, no vivir de la política y crear un ethos en la militancia. Y esto es válido también para quienes ejercen un cargo público: no se puede ver el mismo como ocasión de un jugoso salario, altas dietas, prebendas, cupones de combustible, disputas por viajes al exterior, viáticos y la colocación en empleos de allegados y amigos. Es necesaria, entonces, una nueva moral en el FMLN. No se puede ser un partido de izquierda, con la trayectoria del FMLN, con la identidad y aspiraciones que aquí expresamos, y con una moral de un partido de derecha. Hay que trascender esto mediante la creación de una nueva ética política'.

\section{Conclusión: ¿libanización política, atomiza- ción o resurgimiento del FMLN?}

La crisis del FMLN, que hemos descrito someramente, si no es superada, podría conducirlo a dos salidas igual y altamente peligrosas para el país. Por un lado, a una guerra política interna entre sus diversas facciones o a una especie de libanización -lucha entre diferentes clanes y señores, como en la guerra del Líbano, en que peleaban territorialidad, cuotas de poder, y por eso se mataban entre ellos, terminando por olvidar que su lucha era contra Israel y, en otros casos, pactando con él-, aunque esta libanización en el FMLN sea, en las condiciones actuales, estrictamente política. En todo caso, si el FMLN sigue esta ruta, habrá olvidado el viejo proverbio que reza que "cuando el gato no está bailan los ratones".

Pero también la crisis podría resolverse en la atomización del partido, convirtiéndolo en eterna oposición, irrelevante y sin perspectiva de poder, hasta llegar a la muerte por inanición. Estas dos posibles salidas a la crisis no son incompatibles con soluciones intermedias como, por ejemplo, que se "resuelva" la crisis mediante negociaciones de cuotas de poder y candidaturas para que probablemente algunos, como los niños, mientras tengan un juguete en sus manos, no lloren ni gruñan. Pero una izquierda así no tiene futuro ni razón de ser y, mucho menos, es beneficiosa para el país y, por lo tanto, debe desaparecer, aunque su espacio sea llenado por sectas políticas y por partidos minúsculos, oportunistas, de centro, de izquierda, o como se quieran llamar.

Pero la crisis, a nuestro juicio, puede y debe ser superada, por respeto a la memoria de los caí-

6. He desarrollado ampliamente este tema en un artículo de próxima publicación y, por ello, creo innecesario cansar al lector con una disertación al respecto. 
dos en la lucha y a las víctimas del conflicto y por respeto a las mayorías del país, que merecen algo mucho mejor que ser gobernados por sus opresores, explotadores y verdugos. $\mathrm{Y}$ en este caso, el FMLN resurgiría renovado y firme, con nuevas ideas y con un nuevo liderazgo democrático e institucional, con una nueva visión de sus relaciones con las diversas fuerzas sociales y con mayor responsabilidad histórica. Pero esta salida - la que muchos deseamos - no es posible sin identificar y aceptar la crisis, y sin recorrer el camino de supe- ración que hemos trazado y que, en nuestra opinión, es el correcto.

El FMLN tiene en sus manos, entonces, la libanización o atomización del partido o la superación de la crisis y su resurgimiento. Esperamos que la razón se imponga y que resurja como una fuerza viva y pujante, capaz de sacar al país adelante en beneficio de las mayorías pobres y desposeídas.

San Salvador, abril de 1999. David López 